\title{
Dual Y-Shaped Monopole Antenna for Dual-Band WLAN/WiMAX Operations
}

\author{
Huiqing Zhai, Qiqiang Gao, Zhihui Ma, and Changhong Liang \\ National Key Laboratory of Antennas and Microwave Technology, School of Electronic Engineering, Xidian University, \\ No. 2 South Taibai Road, Xian, Shaanxi 710071, China \\ Correspondence should be addressed to Huiqing Zhai; hqzhai@mail.xidian.edu.cn
}

Received 13 January 2014; Revised 23 April 2014; Accepted 1 June 2014; Published 15 June 2014

Academic Editor: Ahmed A. Kishk

Copyright (C) 2014 Huiqing Zhai et al. This is an open access article distributed under the Creative Commons Attribution License, which permits unrestricted use, distribution, and reproduction in any medium, provided the original work is properly cited.

A dual-band design of monopole antenna with two coupled Y-shaped strips for WLAN/WiMAX applications is presented. By the introduction of dual Y-shaped strips, two separated impedance bandwidths of $22.4 \%(3.28 \sim 4.10 \mathrm{GHz})$ and $19.2 \%(4.90 \sim 5.94 \mathrm{GHz})$ can be obtained to meet the specifications of the WLAN/WiMAX communication band applications. The proposed antenna is successfully simulated, designed, and measured, demonstrating the matched impedance and good radiation characteristics with an overall dimension of $17.7 \times 26 \times 1 \mathrm{~mm}^{3}$.

\section{Introduction}

The rapid development of wireless communication urges the need of antennas covering multiple bands with good radiation characteristics. Thus, many researchers have being paying much attention to design this kind of antennas, such as in [1-9]. In [1], by the presence of an L-shaped parasitic strips, three resonant modes of the antenna for the 2.6/3.5/5.5 GHz-bands can be excited to meet the WiMAX system. By introducing dual U-shaped strips, multiresonant modes for WiMAX applications are proposed in [2]. In [3], with inclusion of an additional small radiation patch, a dual-band antenna designed from 3.1 to $10.6 \mathrm{GHz}$ out of the band $5.0-6.0 \mathrm{GHz}$ can be achieved. Two stacked Tshaped monopoles antenna was presented for $2.4 / 5.2 \mathrm{GHz}$ WLAN-bands applications in [4]. A microsrip-fed dual Ushaped printed monopole antenna design for 2.4 and $5.8 \mathrm{GHz}$ communication bands was introduced in [5]. A novel coplanar waveguide (CPW) antenna was proposed for dual-band WLAN applications in [6]. In [7], by etching an n-shaped slot on the radiating element, a novel coplanar waveguide- (CPW) fed printed monopole antenna was proposed. In [8-10], other three different dual-band antennas were also presented by driven strip, modified half-bowtie radiating element, and variable frequency band-notch characteristic, respectively. Though new structures or designs have been given in above literatures, some shortcomings still exist to a certain extend. For the antennas in $[1,2,4-6]$, the working bands cannot be separately adjusted flexibly. The structures in $[3,7]$ are designed for tunable notches, which may lead to inconstant impedance bandwidth of each operation band. Meanwhile, antennas in [8-10] have complex constructions which will somehow limit their low-cost terminal design in large-scale wireless communications. Besides, the overall dimensions of antenna are with large size, for example, $100 \times 100 \times 56 \mathrm{~mm}^{3}$ in [11], $32.5 \times 20 \times 1 \mathrm{~mm}^{3}$ in [12], and $30 \times 26 \times 1.6 \mathrm{~mm}^{3}$ in [13].

In this paper, a new design of dual-band monopole antenna with two coupled Y-shaped strips for WLAN/ WiMAX applications is proposed. With the usage of two Y-shaped strips, both $5.2 / 5.8 \mathrm{GHz}$ WLAN bands and 3.6/5.5 GHz WiMAX bands can be obtained. Specially, the presented antenna has the advantages of small size, simple structure, and steady gain. At the same time, both working bands can be separately adjusted by simple central angle of the up Y-shaped strip. The simulated and measured results show that the antenna can effectively cover two separated impedance bandwidths including $820 \mathrm{MHz}(3.28 \sim 4.10 \mathrm{GHz})$ 


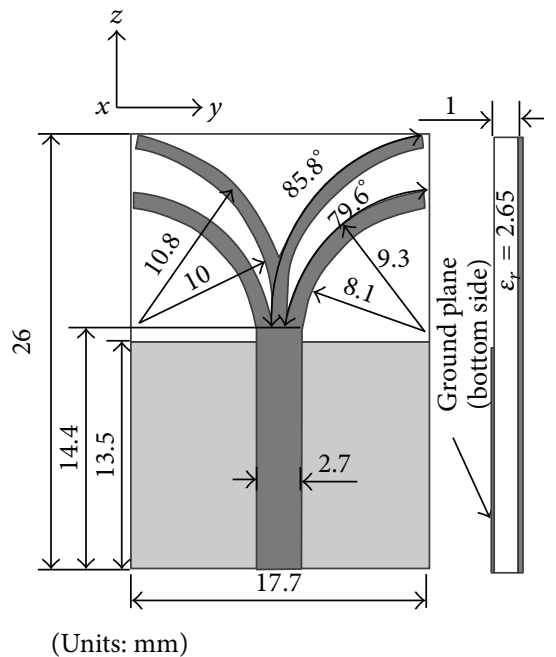

FIGURE 1: The geometry of the presented dual-band antenna.

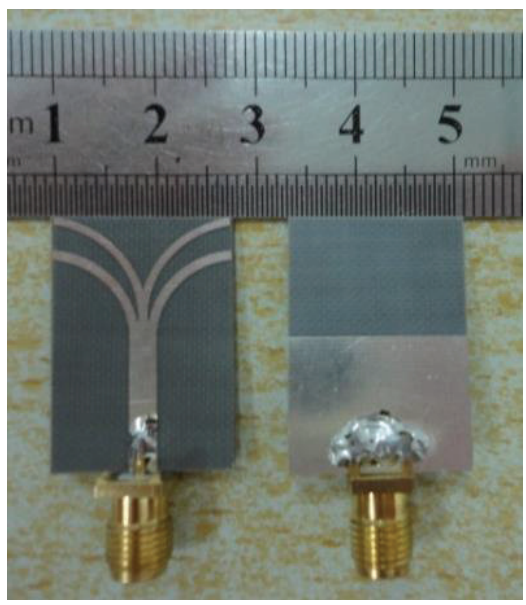

FIGURE 2: The fabricated prototype of the presented antenna.

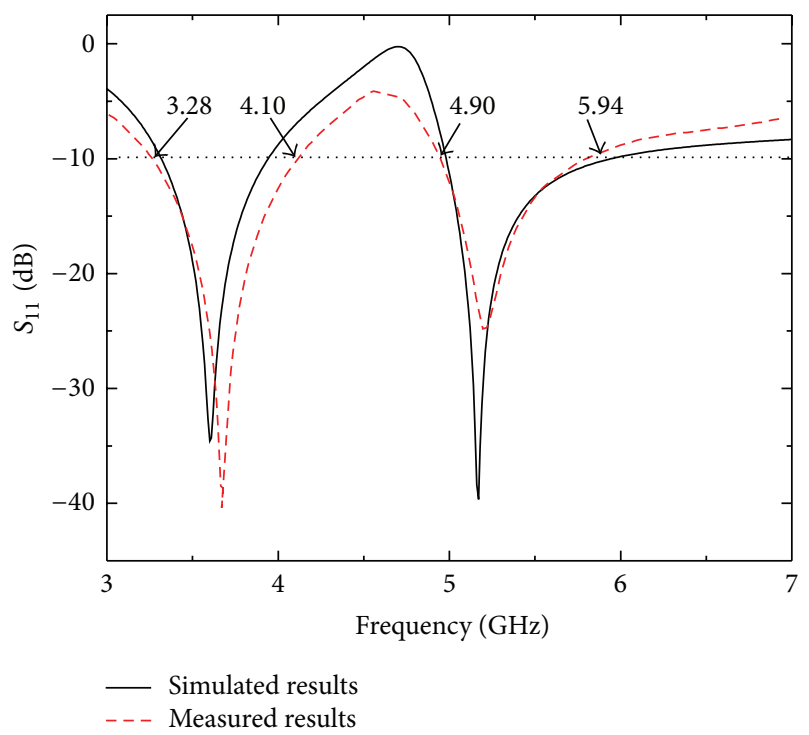

FIgURE 3: The simulated and measured return loss results of the proposed antenna.

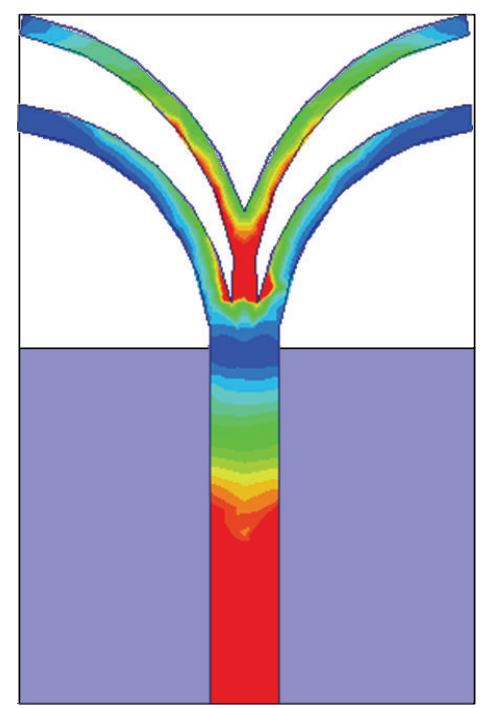

$J_{\text {surf }}$ [A_per_m]

$3.5000 e+001$

$3.2557 e+001$

$3.0114 e+001$

$2.7672 e+001$

$2.5229 e+001$

$2.2786 e+001$

$2.0343 e+001$

$1.7900 e+001$

$1.5458 e+001$

$1.3015 e+001$

$1.0572 e+001$

$8.1291 e+000$

$5.6863 e+000$

$3.2435 e+000$

$8.0072 e-001$

(a)

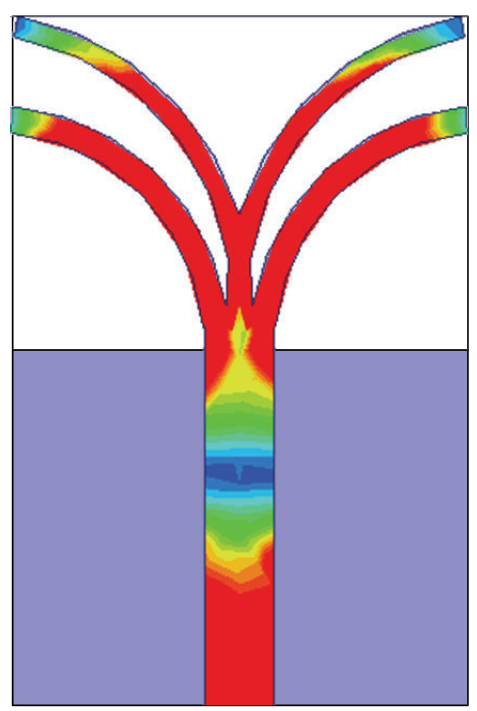

$J_{\text {surf }}[$ A_per_m]

$3.5000 e+001$

$3.2557 e+001$

$3.0114 e+001$

$2.7672 e+001$

$2.5229 e+001$

$2.2786 e+001$

$2.0343 e+001$

$1.7900 e+001$

$1.5458 e+001$

$1.3015 e+001$

$1.0572 e+001$

$8.1291 e+000$

$5.6863 e+000$

$3.2435 e+000$

$8.0072 e-001$

FIgURE 4: The current distributions on radiation patches. (a) The current distributions at $3.60 \mathrm{GHz}$ and (b) the current distributions at $5.17 \mathrm{GHz}$.

and $1040 \mathrm{MHz}(4.90 \sim 5.94 \mathrm{GHz})$. The proposed antenna has a low profile and can be easily fed by using a $50 \Omega$ microstrip line with the overall dimension of $17.7 \times 26 \times 1 \mathrm{~mm}^{3}$. Good radiation characteristics of the antenna can also be obtained, which are verified by the simulated and measured results.

\section{Design and Analysis of Dual-Band Y-Shaped Antenna}

Figure 1 illustrates the geometry and configuration of the proposed monopole antenna with two coupled Y-shaped strips for WLAN/WiMAX applications. A $50 \Omega$ microstrip line is etched as the feeding structure on one side of the substrate with dielectric constant of 2.65 and a thickness of 


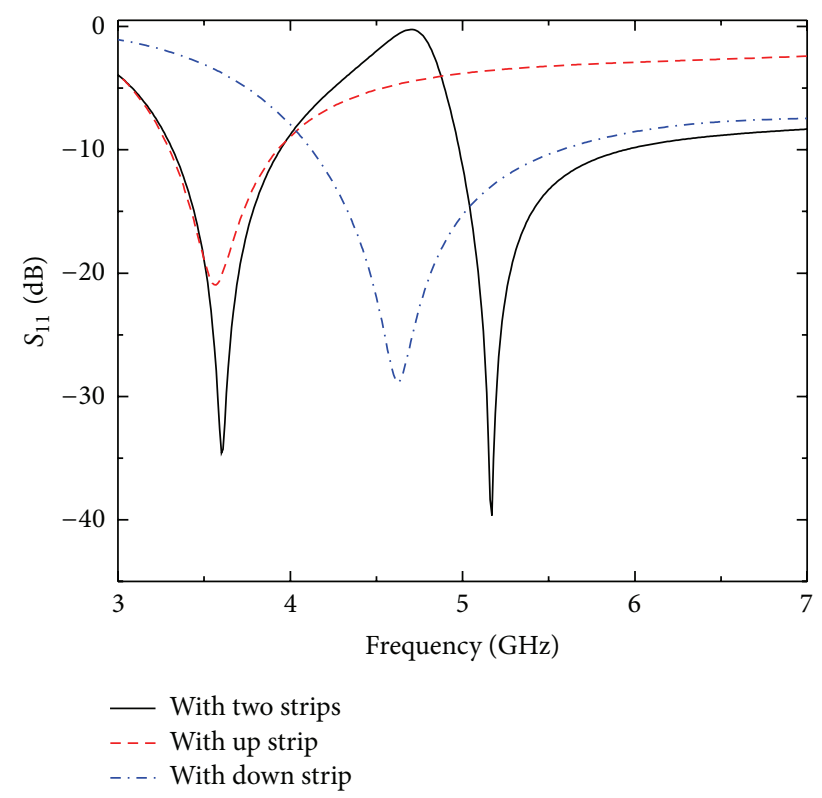

Figure 5: The simulated return loss of the presented antenna with two strips, without up or down strips.

$1 \mathrm{~mm}$. On the other side of the dielectric substrate, a ground plane is printed below the microstrip feed line.

The practical fabricated dual Y-shaped monopole antenna is shown in Figure 2. The overall dimension of the antenna is $17.7 \times 26 \times 1 \mathrm{~mm}^{3}$. The simulated and the measured results are achieved by using the commercial simulation software HFSS and the Agilent E8357A vector network analyzer, respectively. The simulated and measured return loss results of the proposed dual-band antenna are shown in Figure 3, which have good agreement with each other. According to measured results, the antenna can effectively cover two separated impedance bandwidths of $820 \mathrm{MHz}(3.28 \sim 4.10 \mathrm{GHz})$ and $1040 \mathrm{MHz}(4.90 \sim 5.94 \mathrm{GHz})$, which can be well applied to 5.2/5.8 GHz WLAN bands and 3.6/5.5 GHz WiMAX bands.

In order to show the mechanism of the presented antenna, Figure 4 shows the surface current distributions of the proposed antenna at two different frequencies. When the antenna is working at near $3.60 \mathrm{GHz}$, much surface current distributes at the up Y-shaped strip, which means that its resonance mode has been excited at $3.60 \mathrm{GHz}$. We also know that much surface current distributes at both the up and down Y-shaped strips, which means that both of them provide the contribution for the resonance mode at $5.17 \mathrm{GHz}$. What is more, the central frequency of the two bands can be approximately calculated by

$$
\begin{gathered}
f=\frac{c}{4 \sqrt{\varepsilon_{\text {eff }}} \cdot L_{\text {total }}}, \\
\varepsilon_{\text {eff }}=\frac{\left(\varepsilon_{r}+1\right)}{2},
\end{gathered}
$$

where $c$ is the speed of light, $\varepsilon_{\text {eff }}$ is the effective relative permittivity, $\varepsilon_{r}$ is the relative permittivity, and $L_{\text {total }}$ is the total length of Y-shaped strips. Clearly, the length of each strip is

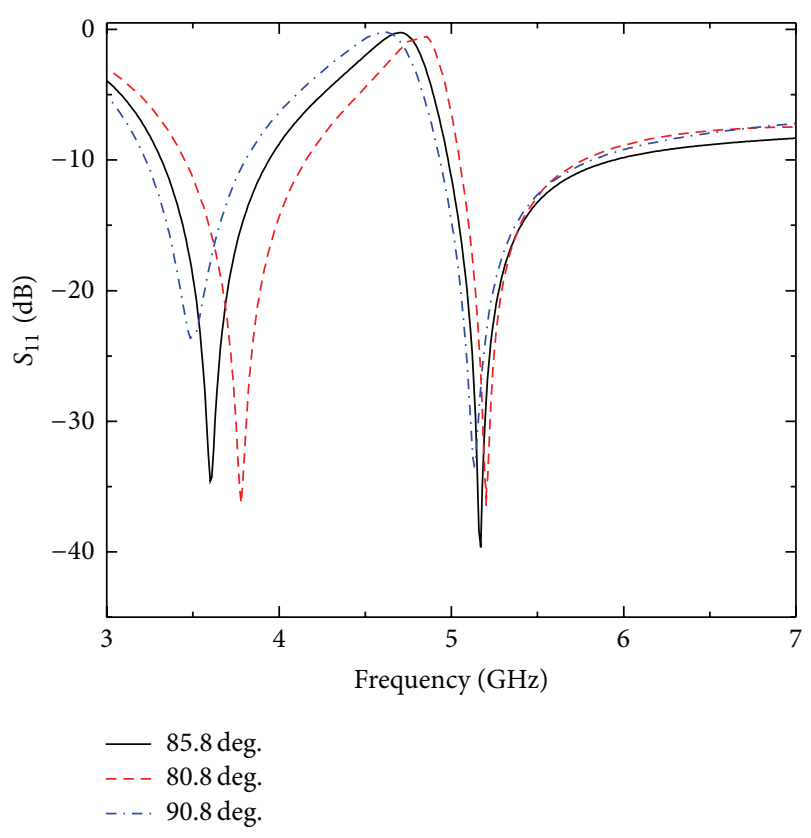

(a)

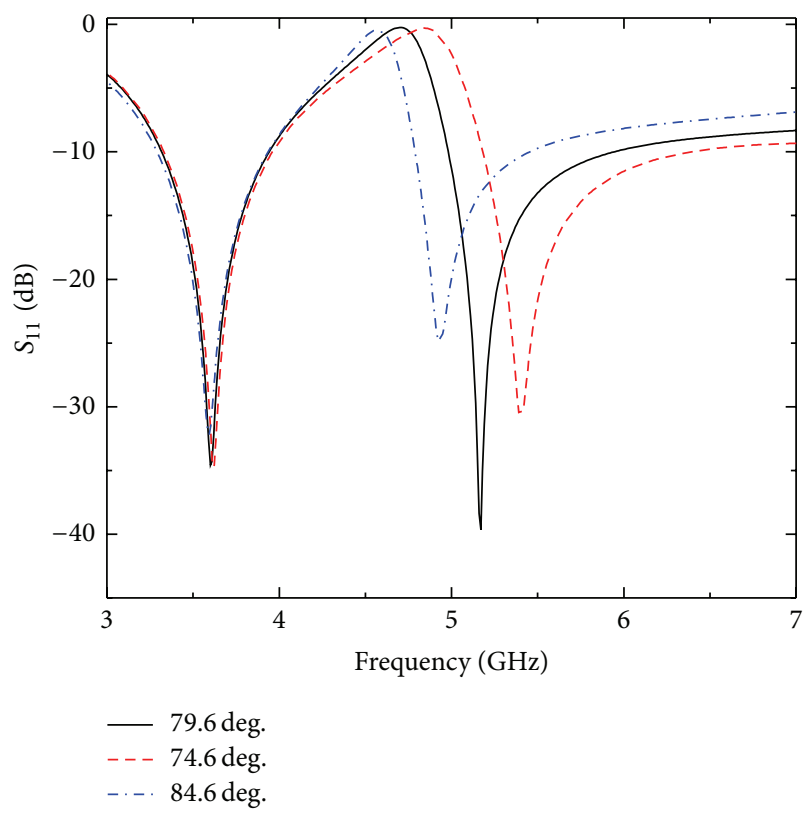

(b)

Figure 6: The return loss of the proposed antenna with the central angle parameters. (a) Central angle of the up Y-shaped strip. (b) Central angle of the down Y-shaped strip.

about a quarter of the guided wavelength $\lambda \mathrm{g}$. From Figure 5, it can be seen that the up Y-shaped strip provides the low resonance frequency at $3.56 \mathrm{GHz}$, and the down Y-shaped strip resonates at $4.63 \mathrm{GHz}$. By connecting with the two Yshaped strips, the proposed antenna can cover two bands we desired. It means that the operation bands can be determined by both the two Y-shaped strips and the coupling of the two strips.

In order to analyze the affection of the central angle on the antenna's return loss, Figures 6(a) and 6(b) show how 


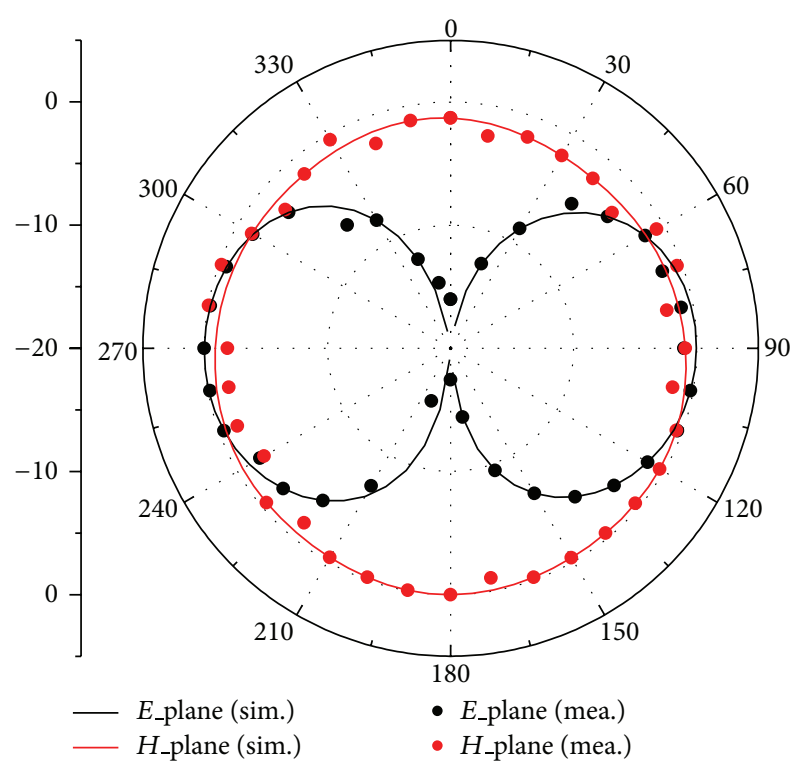

(a)

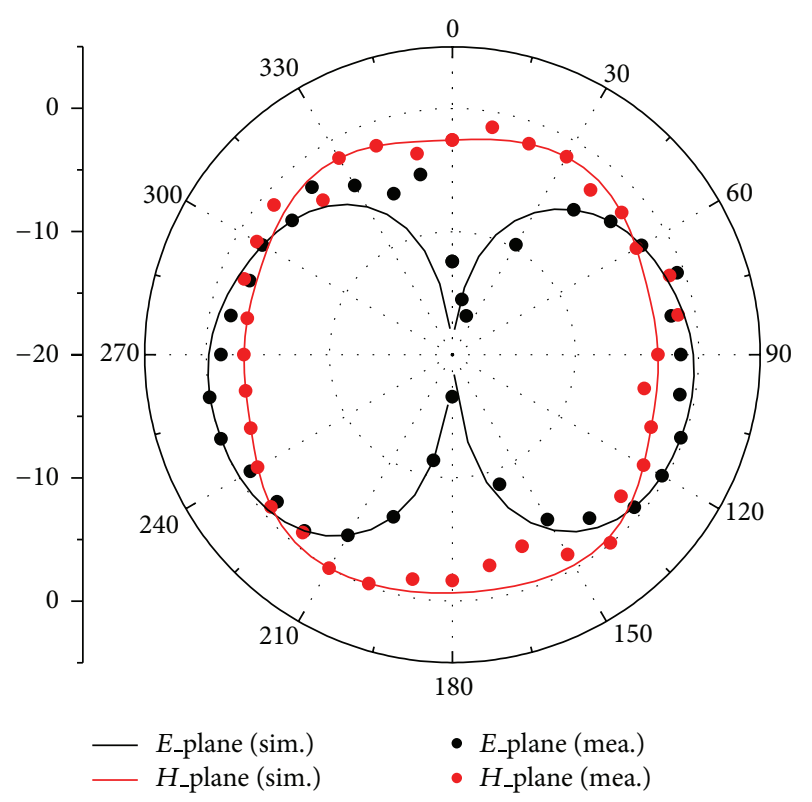

(b)

FIGURE 7: Simulated and measured normalized radiation patterns (unit: $\mathrm{dBi}$ ). (a) $E$-plane and $H$-plane at $3.60 \mathrm{GHz}$. (b) $E$-plane and $H$-plane at $5.17 \mathrm{GHz}$.

the return loss of the presented antenna changes with the central angle parameters of the two Y-shaped strips. From Figure 6(a), when the central angle of up Y-shaped strip is changed from $85.8 \mathrm{deg}$. to $90.8 \mathrm{deg}$., the low frequency band becomes distinctly lower and lower though the high working band has a slight shift, resulting from small couplings of two Y-shaped strips for the resonance mode at $5.17 \mathrm{GHz}$, shown in Figure 4(b). On the other hand, from Figure 6(b), we also know that the higher frequency band can be obviously adapted as the central angle of down Y-shaped strip is changed, in the case of keeping the lower working band

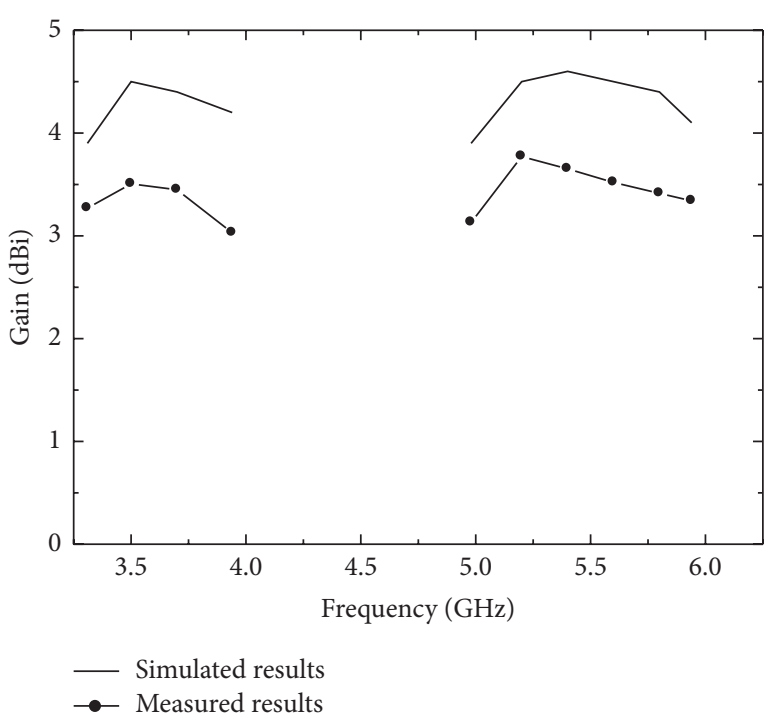

FIGURE 8: Simulated and measured peak gains of the proposed antenna for the two desired bands.

nearly unchanged, which can be explained by the current distributions in Figure 4(a). In a word, the two bands of present dual-band antenna can be basically independently controlled by main physical parameters.

In Figure 7, the simulated and measured normalized radiation patterns for the antenna are shown. The antenna's $E$ plane ( $x$ - $z$ plane) and $H$-plane ( $x-y$ plane) radiation pattern at $3.60 \mathrm{GHz}$ is shown in Figure 7(a). The $E$-plane and $H$ plane radiation patterns at $5.17 \mathrm{GHz}$ are shown in Figure 7(b). It can be observed that the simulated results and measured results are in good agreement and good omnidirectional patterns are obtained for the two frequency bands in $x-y$ plane, and close to bidirectional patterns in $x-z$ planes are achieved. Figure 8 illustrates the simulated and measured peak gains of the proposed antenna. According the measured results, their peak gains are about $3.51 \mathrm{dBi}, 3.77 \mathrm{dBi}, 3.58 \mathrm{dBi}$, and $3.41 \mathrm{dBi}$ at $3.6 \mathrm{GHz}, 5.2 \mathrm{GHz}, 5.5 \mathrm{GHz}$, and $5.8 \mathrm{GHz}$, respectively. The present monopole antenna provides good radiation characteristics at the two working frequency bands from what is mentioned above.

\section{Conclusion}

In this research, a dual-band design of monopole antenna with two coupled Y-shaped strips for WLAN/WiMAX applications is presented and implemented. By introducing the dual Y-shaped strips, two separated bands can be effectively achieved, which is verified by simulated and measured results. The antenna also gives good radiation characteristics at the two desired working frequency bands.

\section{Conflict of Interests}

The authors declare that there is no conflict of interests regarding the publication of this paper. 


\section{Acknowledgments}

This work is supported by the NSFC under Contract no. 61101066, the Natural Science Basic Research Plan in Shaanxi Province of China under Grant no. 2014JM8316, Fundamental Research Funds for the Central Universities (JB140232), Huawei Innovation Research Program, and Foundation for the Returned Overseas Chinese Scholars in Shaanxi Province.

\section{References}

[1] J.-H. Lu and B.-J. Huang, "Planar multi-band monopole antenna with L-shaped parasitic strip for WiMAX application," Electronics Letters, vol. 46, no. 10, pp. 671-672, 2010.

[2] J.-H. Lu and W.-C. Chou, "Planar dual U-shaped monopole antenna with multiband operation for IEEE 802.16e," IEEE Antennas and Wireless Propagation Letters, vol. 9, pp. 1006-1009, 2010.

[3] K. G. Thomas and M. Sreenivasan, "A simple ultrawideband planar rectangular printed antenna with band dispensation," IEEE Transactions on Antennas and Propagation, vol. 58, no. 1, pp. 2734, 2010.

[4] Y.-L. Kuo and K.-L. Wong, "Printed double-T monopole antenna for 2.4/5.2 Ghz dual-band WLAN operations," IEEE Transactions on Antennas and Propagation, vol. 51, no. 9, pp. 2187-2192, 2003.

[5] I.-F. Chen and C.-M. Peng, "Microstrip-fed dual-U-shaped printed monopole antenna for dual-band wireless communication applications," Electronics Letters, vol. 39, no. 13, pp. 955-956, 2003.

[6] K. G. Thomas and M. Sreenivasan, "Compact CPW-fed dualband antenna," Electronics Letters, vol. 46, no. 1, pp. 13-14, 2010.

[7] S. T. Fan, Y. Z. Yin, W. Hu, K. Song, and B. Li, "Novel CPW-FED printed monopole antenna with an n-shaped slot for dual-band operations," Microwave and Optical Technology Letters, vol. 54, no. 1, pp. 240-242, 2012.

[8] K.-L. Wong and T.-W. Kang, "GSM850/900/1800/1900/UMTS printed monopole antenna for mobile phone application," Microwave and Optical Technology Letters, vol. 50, no. 20, pp. 3192-3198, 2008.

[9] Y. J. Cho, K. H. Kim, D. H. Choi, S. S. Lee, and S.-O. Park, "A miniature UWB planar monopole antenna with $5-\mathrm{GHz}$ bandrejection filter and the time-domain characteristics," IEEE Transactions on Antennas and Propagation, vol. 54, no. 5, pp. 1453-1460, 2006.

[10] M. Ojaroudi, G. Ghanbari, N. Ojaroudi, and C. Ghobadi, "Small square monopole antenna for UWB applications with variable frequency band-notch function," IEEE Antennas and Wireless Propagation Letters, vol. 8, pp. 1061-1064, 2009.

[11] H. J. Zhou, Q. Z. Liu, Y. Z. Yin, and W. B. Wei, "Study of the band-notch function for swallow-tailed planar monopole antennas," Progress in Electromagnetics Research, vol. 77, pp. 5565, 2007.

[12] J. Ma, Y. Z. Yin, S. G. Zhou, and L. Y. Zhao, "A new ultra-wideband microstrip-line fed antenna with $3.5 / 5.5 \mathrm{GHz}$ dual bandnotch function," Progress In Electromagnetics Research Letters, vol. 7, pp. 79-85, 2009.

[13] Q.-X. Chu and Y.-Y. Yang, "3.5/5.5 GHz dual band-notch ultrawideband antenna," Electronics Letters, vol. 44, no. 3, pp. 172174, 2008. 

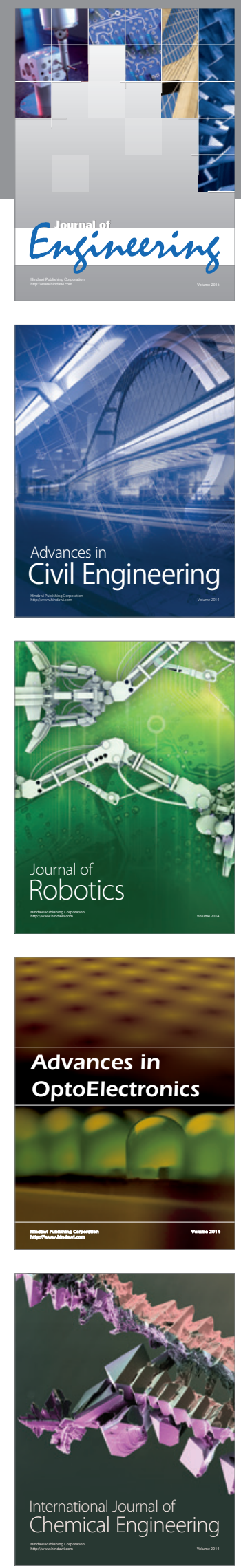

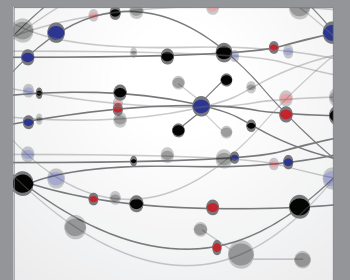

The Scientific World Journal
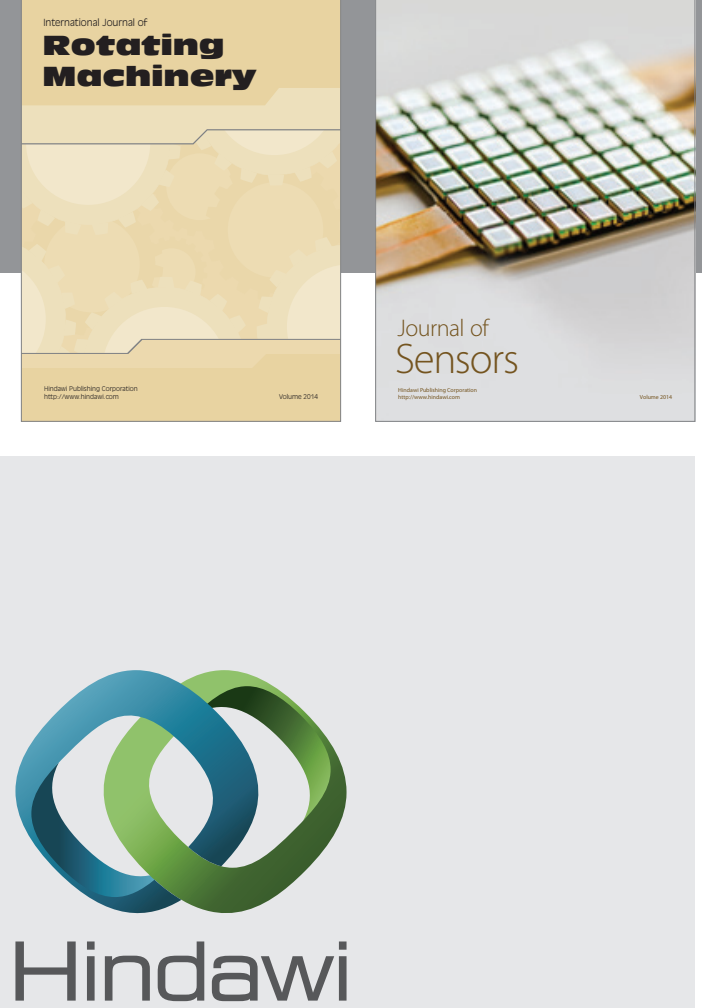

Submit your manuscripts at http://www.hindawi.com
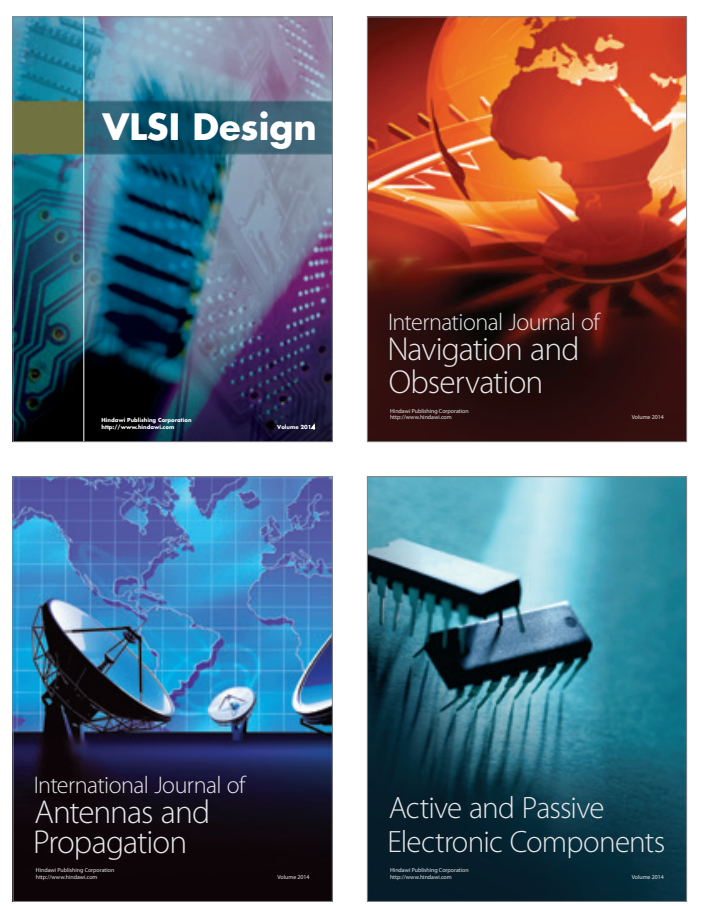
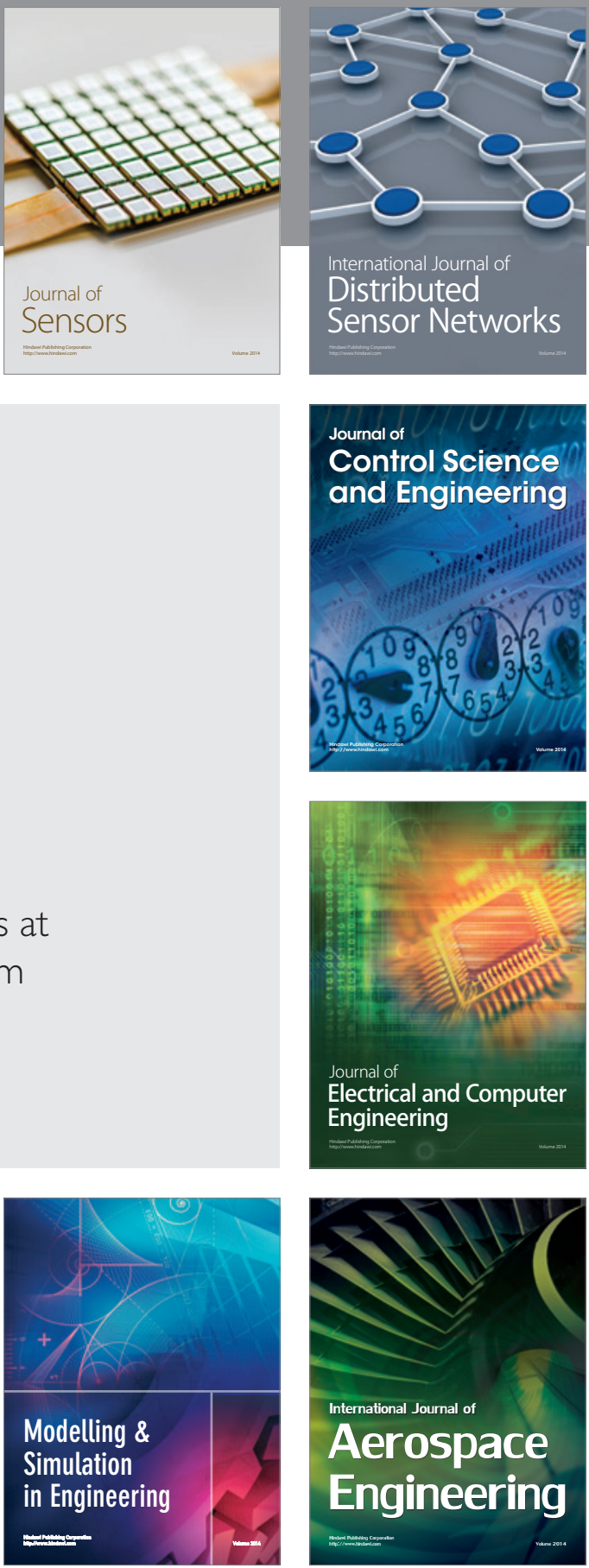

Journal of

Control Science

and Engineering
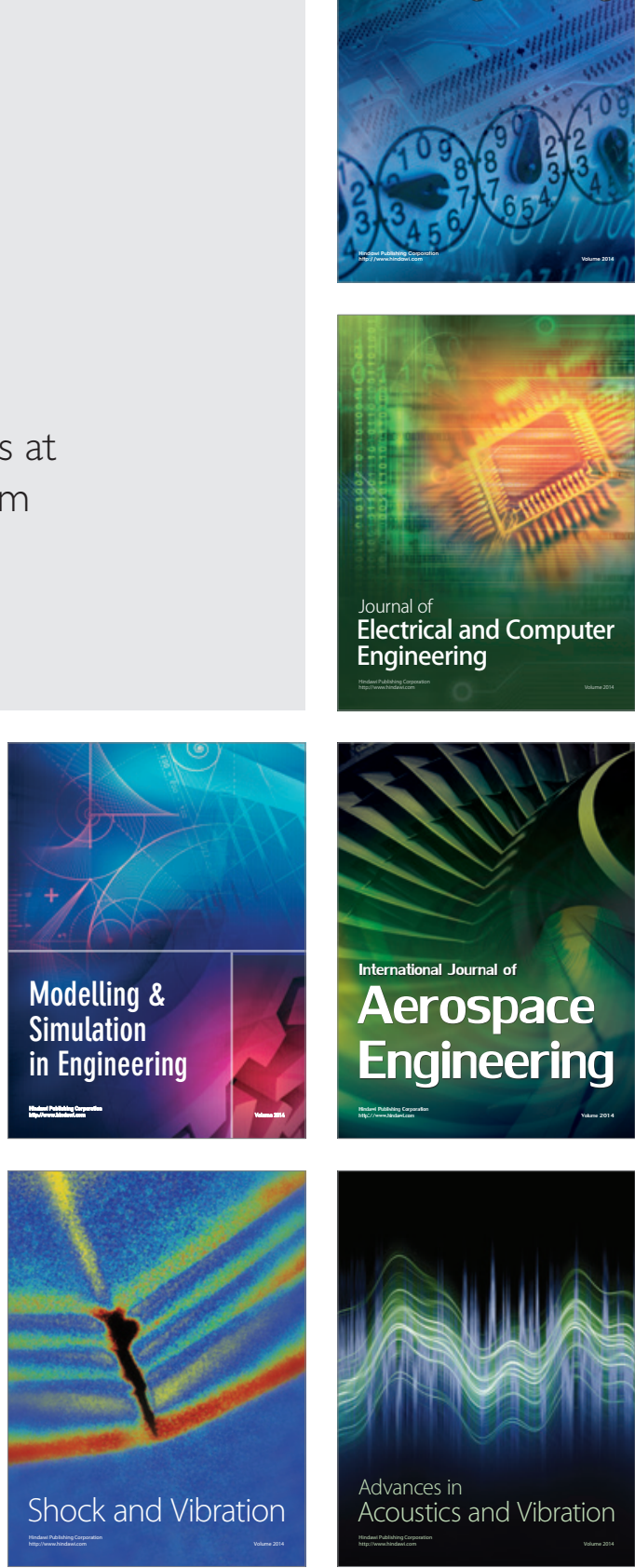